\title{
Sociodemography and Distribution of Students Attending Schools for the Blind in Oyo State, Nigeria
}

\author{
AL Mosuro", AI Ajaiyeoba ${ }^{2}$, CO Bekibele ${ }^{3}$, MS Eniola (PhD) ${ }^{4}$, B Adedokun ${ }^{5}$ \\ ${ }^{1}$ Consultant Ophthalmologist, Department of Ophthalmology, General Hospital Lagos Island, Lagos State, Nigeria. \\ ${ }^{2}$ Professor of Ophthalmology and Dean of Clinical Sciences, College of Medicine, University of Ibadan, Oyo State, Nigeria \\ ${ }^{3}$ Consultant Ophthalmologist and Senior Lecturer, Department of Ophthalmology, University College Hospital, Ibadan, Oyo State, \\ Nigeria \\ ${ }^{4}$ Senior Lecturer, Department of Special Education, University of Ibadan, Oyo State, Nigeria \\ ${ }^{5}$ Lecturer, Department of Epidemiology, Medical Statistics and Environmental Health, University of Ibadan, Oyo State, Nigeria.
}

\section{ABSTRACT}

Aim: To determine the distribution and sociodemographic classification of students attending schools for the blind in Oyo State, Nigeria.

Method: This is a descriptive and interventional crosssectional study. A total sampling of all students in the four schools for the blind in Oyo State was carried out.

Results: A total of 86 students from the four schools for the blind in Oyo State were included in the study. This comprised 2(2.3\%) students from School for the Deaf and Blind, Eruwa; 22 (25.6\%) from School for the Blind, Aperin Oniyere, Ibadan; 11 (12.8\%) from School for the Blind, Doba, Oyo Town; and 51 (59.1\%) from Ogbomosho Training Centre for the Blind, Ogbomosho. The mean age of the students was 19.4 years $(\mathrm{SD}=8.19)$. Thirty percent of the students were less than 16 years, $33.7 \%$ were between 17 and 19 years, $16.3 \%$ were between 20 and 24 years, $8.1 \%$ between 25 and 29 years, and $11.6 \%$ were above 30 years. There were more males $(73.3 \%)$ than females $(26.7 \%)$, with a male to female ratio of $3: 1$. Christians constituted $73.3 \%$ of the students while Muslims made up the remainder. Majority were from the Yoruba ethnic group (98.9\%).

Conclusion: More attention needs to be focussed on the sociodemography and distribution of students in schools for the blind in Nigeria as this will assist government and non governmental agencies in the planning and implementation of policies which will help to improve the lot of the students in the schools.

Keywords: Distribution, sociodemography, students, schools for the blind, Oyo State

\section{INTRODUCTION}

Childhood blindness is considered a priority of 'Vision 2020 - The Right to Sight' ${ }^{1,2}$ This is a global initiative for the elimination of avoidable blindness. One million, four hundred thousand (1.4 million) of the 45 million people estimated to be blind worldwide are children. ${ }^{3}$ One million of them live in Asia and approximately 300,000 in Africa. ${ }^{1,2}$ Preventing childhood blindness is a priority to the Vision 2020 initiative because blind children have a lifetime of blindness ahead of them. ${ }^{1,2}$ This lifetime includes problems with opportunities for education, employment, earning potential and social relationships. ${ }^{1,2}$ Early onset blindness can also have grave adverse effects on social, emotional and psychomotor development. ${ }^{1,2}$ It is a well documented fact that blind children have a higher death rate than their sighted counterparts. ${ }^{1,2}$

The provision of low vision services and aids to the students with low vision, who have always been referred to as blind, can help to enhance their residual vision and improve their quality of life.

An estimated 500,000 children become blind each year; $60 \%$ of blind children in developing countries die within a year of becoming blind. ${ }^{1,2}$ Almost half of all the cases of blindness in children in the developing countries of Africa and Asia are due to avoidable causes that can easily be treated or prevented. ${ }^{1,2}$ The prevalence of blindness is higher in developing countries because of the prevalence of potentially blinding yet avoidable conditions which abound and are poorly managed due to inadequate health facilities and shortage of trained medical personnel. ${ }^{1,2}$

In Nigeria, very little has been done in this field of study. In a study by Akinsola and Ajaiyeoba ${ }^{3}$ carried out in a school for the blind in Lagos, Nigeria, twenty-six children aged below 16 years were identified as having low vision and blindness and were examined to determine the causes.

${ }^{*}$ Correspondence: Dr A.L. Mosuro, Department of Ophthalmology, General Hospital Lagos Island, Lagos State, Nigeria • email: damosuro@yahoo.com 
Ezegwui et al. ${ }^{4}$ carried out a cross-sectional study to identify the major causes of severe visual impairment/ blindness (SVI/BL) among students in schools for the blind in south-eastern Nigeria.

Foster $^{5}$, and Kello and Gilbert ${ }^{6}$ carried out well documented studies in Ethiopia, highlighting the sociodemographic data of students in the schools for the blind and the types and causes of blindness. Ntim-Amponsah's ${ }^{7}$ study in Ghana also included important socio-demographic data.

There has been no study on the socio-demographic data of students in schools for the blind in Oyo State. Such a study is necessary for strategic planning and implementation of policies by the stakeholders - government and non governmental agencies - for the benefit of the students in the schools.

The aim of this study is to determine the distribution and socio-demographic classification of the students attending schools for the blind in Oyo State, Nigeria.

\section{MATERIALS AND METHODS}

\section{Study Area}

Oyo State is located in the southwestern region of Nigeria and is one of the 36 states in the country. It has 33 local government areas and a population of 5.6 million people (National Population Census 2006). ${ }^{8}$ The major ethnic group is Yoruba, although other ethnic groups are also present in the state. Ibadan is the capital of the state. Most of the people who reside in urban areas are civil servants, while those who reside in the suburban regions include civil servants, artisans, traders and farmers. There are a total of four schools for the blind in Oyo State.

\section{Study Site}

The study was carried out in all the schools for the blind in Oyo State, a list of which was obtained from the state's Ministry of Education, Special Education Unit. The schools are: Ogbomosho Training Centre for the Blind, Ogbomosho; School for the Blind, Doba, Oyo Town; School for the Blind, Aperin Oniyere, Ibadan; and the School for the Deaf and Blind, Eruwa.

\section{Study Design}

It is a descriptive and interventional cross-sectional study.

\section{Sample Size}

The minimum sample size was determined by using the Kish and Leslie formula for estimating a single proportion. This is expressed as:

$$
n=Z_{\alpha}^{2} p q / d^{2}
$$

where:

$$
\begin{aligned}
& n=\text { minimum sample size } \\
& Z_{\alpha}=\text { standard normal deviate when } \alpha \text { is } 0.05=1.96 \\
& \alpha=\text { probability of having a type I error }
\end{aligned}
$$

$p=$ prevalence of low vision amongst blind students in a 2003 study in eastern Nigeria

$=2.4 \%\left(\right.$ Ezegwui et al., 2003) ${ }^{4}$

$q=1-p$

$d=$ level of precision $=5 \%$

This gives a minimum sample size of 36 . Allowing for a

non response rate of $10 \%$, the minimum sample size was 40 .

Since the interest of the study was the entire state, a total sampling was carried out because the total blind student population in the schools for the blind in Oyo State outnumbers the number enumerated in the sample size. Thus the study has adequate power.

\section{Sampling Technique}

A total sampling of all students in the schools for the blind in Oyo State was carried out. All the students were assessed by the investigators for visual acuity and associated pathologies and physical handicap. A questionnaire was administered to the students with the assistance of the school heads and teachers. Instruments that were used include:

- Snellen's chart

- Illiterate E chart

- LogMAR chart

- Lea picture charts

- Near visual acuity charts

- Keeler® brand retinoscope

- Trial frame and trial box with trial lenses

- Pin hole, pen torch

- Welch Allyn ${ }^{\circledR}$ direct ophthalmoscope and indirect ophthalmoscope

- Perkins ${ }^{\circledR}$ hand-held tonometer

- Fluorescein (Fluorescein sodium Ph.Eur 1mg) strips

- Tetracaine hydrochloride $0.5 \%$ anaesthetic eye drops

- Tropicamide $1 \%$ dilating drops

- Phenylephrine hydrochloride 5\% dilating drop

- Crayola ${ }^{\circledR}$ brand colour crayons

- Hand-held magnifiers

- Stand magnifiers

- Telescopes

- A tape rule

Students that could not comprehend the questions asked, and that could not respond appropriately were excluded from the study.

\section{Data Collection Procedure}

Permission was obtained from the school authorities and consent was sought from the parents of the subjects. Local ethical clearance was obtained from both the Ethical Committees of the University College Hospital (UCH), Ibadan, and the Ethical Review Committee of the Oyo State Ministry of Health. The study was explained to the parents, teachers, students, and school authorities, and their consent and cooperation sought. 


\section{Data Management and Analysis}

- The data collected was checked for errors by the investigators. It was then analysed using the SPSS version 10 statistical package. Data was also checked for errors after entry. Variables were summarized by the investigators using means and standard deviation for quantitative variables, frequencies and proportions for qualitative variables.

- Distribution of types of blindness, causes, associated pathologies and types of visual aid devices needed were summarized by the investigator using proportions. The relationship between low vision and the sociodemographic characteristics of the students was tested using the chi square test at $5 \%$ level of significance.

\section{RESULTS}

Eighty six (86) students were studied in the four schools for the blind in Oyo State. This comprised 2 students $(2.3 \%)$ from the School for the Deaf and Blind, Eruwa; 22 (25.6\%) from School for the Blind, Aperin Oniyere, Ibadan, 11(12.8\%) from School for the Blind, Doba, Oyo Town; and 51 (59.1\%) from Ogbomosho Training Centre for the Blind, Ogbomosho. The mean age of the students was 19.4 years $(\mathrm{SD}=8.19)$ while the age range was from 9 to 35 years. The largest age group among the students (33.7\%) were between 16 and 19 years. Among the others, $30 \%$ were less than 16 years, $16.3 \%$ were between 20 and 24 years of age, $8.1 \%$ between 25 and 29 years, and $11.6 \%$ above 30 years of age (summarized in table $1)$. There were more males $(73.3 \%)$ than females $(26.7 \%)$, with a male to female ratio of $3: 1$. There was no female student aged over 24 years in any of the schools. The age-sex distribution is summarized in figure 1. Christians constituted $73.3 \%$ of the students while Muslims made up the remainder. Majority were from the Yoruba ethnic group $(98.8 \%)$. All the students were examined. Of all the students examined, $83(96.5 \%)$ had no associated disabilities, while 5 $(5.8 \%)$ had a positive history of blindness in close relatives.
The most commonest period of onset was from the first year of life to puberty (34 students - 39.5\%), followed by blindness occurring in infancy (27 students - 31.7\%). Blindness occurred the least during adolescence amongst the students studied (4 students $-4.7 \%$ ).

Table 1. Profile of the 86 students attending schools for the blind in Oyo State

\begin{tabular}{|c|c|c|}
\hline Characteristic & Frequency & Percentage \\
\hline \multicolumn{3}{|l|}{ Age group(years) } \\
\hline Less than 16 & 26 & 30.2 \\
\hline $16-19$ & 29 & 33.7 \\
\hline $20-24$ & 14 & 16.3 \\
\hline $25-29$ & 7 & 8.1 \\
\hline $30+$ & 10 & 11.6 \\
\hline \multicolumn{3}{|l|}{ Gender } \\
\hline Male & 63 & 73.3 \\
\hline Female & 23 & 26.7 \\
\hline \multicolumn{3}{|l|}{ Religion } \\
\hline Christianity & 63 & 73.3 \\
\hline Islam & 23 & 26.7 \\
\hline \multicolumn{3}{|l|}{ Ethnic group } \\
\hline Yoruba & 85 & 98.8 \\
\hline Others & 1 & 1.2 \\
\hline \multicolumn{3}{|c|}{ Associated disability } \\
\hline Yes & 3 & 3.5 \\
\hline No & 83 & 96.5 \\
\hline \multicolumn{3}{|c|}{ Blindness in family } \\
\hline Yes & 5 & 5.8 \\
\hline No & 81 & 94.2 \\
\hline \multicolumn{3}{|l|}{ Onset of blindness } \\
\hline Since birth & 9 & 10.5 \\
\hline Neonatal life & 5 & 5.8 \\
\hline Infancy & 27 & 31.7 \\
\hline 1 year to puberty & 34 & 39.5 \\
\hline Adolescence & 4 & 4.7 \\
\hline Adulthood & 8 & 9.3 \\
\hline
\end{tabular}

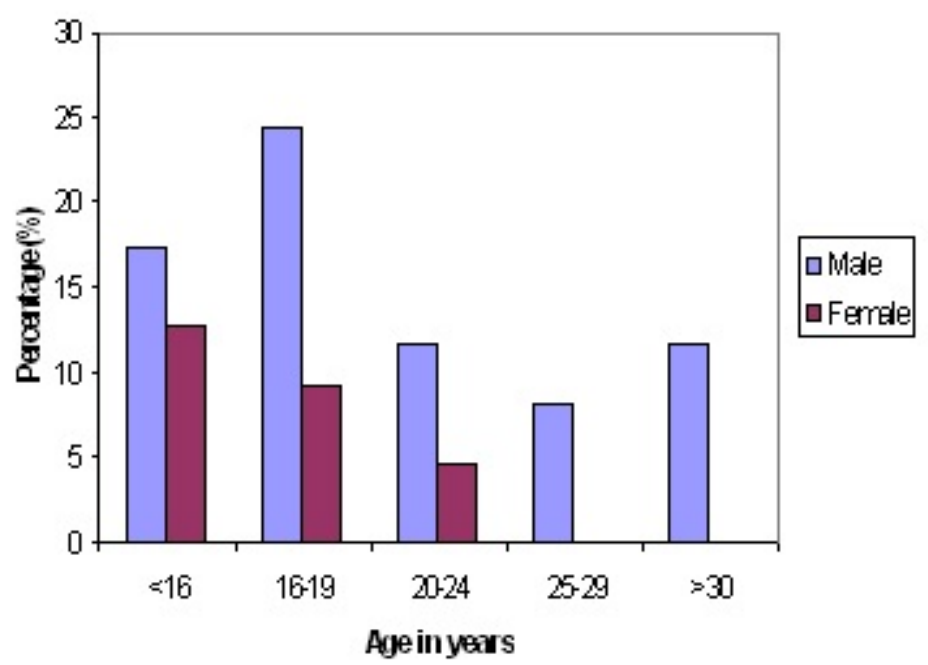

Figure 1. Age-sex distribution of the 86 students attending schools for the blind in Oyo State 


\section{DISCUSSION}

The age range of the students was from 9 to 35 years. The mean age was 19.4 years $(\mathrm{SD}=8.19)$, with $30 \%$ of the students being under 16 years. Bearing in mind the World Health Organization (WHO) reports ${ }^{1,2,9}$ on childhood blindness and its eradication in line with the VISION 2020 initiative, this proportion of students is too significant to be ignored. There are estimated to be 1.4 million blind children worldwide, of whom over $21 \%$ live in sub-Saharan Africa, which includes Nigeria. ${ }^{1-3}$ The prevalence of blindness in children varies according to socioeconomic development (and also according to the mortality rates of children under 5 years of age), ranging from an estimated 0.3 per 1000 children in high-income countries with low under- 5 mortality rates to 1.5 per 1000 children in low-income countries with high under-5 mortality rates. ${ }^{1-3}$ Blind children have a lifetime of blindness ahead of them. This lifetime includes problems with opportunities for education, employment, earning potential and social relationships. ${ }^{1,2}$ Early onset blindness can also have grave adverse effects on social, emotional and psychomotor development. ${ }^{1,2}$ It is a well-documented fact that blind children have a higher death rate than their sighted counterparts. ${ }^{1,2}$

In every age group, there were more male than female students, but there were no female students over 24 years in any of the schools. The high male to female ratio is similar to the results obtained in other studies carried out in developing countries and may be related to the traditional belief that education is more important for the male than for the female child..$^{6,710}$ The female students would have dropped out of school by adolescence to get married. However, differences in the age of the students, age of onset of blindness, gender, religion, ethnicity, associated disability, and family history of blindness obtained in this study were not statistically significant in the overall analysis, which compares to similar African studies ${ }^{3,4,9,11}$ as well as to Asian studies. ${ }^{3,4,10-13}$

Most of the students were from the Ogbomoso and the Ibadan schools which are bigger, better equipped and better staffed. Emphasis should be placed on the training of more teachers for special education as the numbers in the schools visited were not sufficient. Refresher courses should also be organized for the teachers to keep them up to date on current teaching techniques, aids, and services, and on how to use the aids to optimize the students' residual vision.

\section{CONCLUSION}

More attention needs to be focused on the socio-demography and distribution of students in schools for the blind in Nigeria. This will enable government and non governmental agencies to plan and implement policies which will help to improve the lot of the students in the schools for the blind. Far-reaching grassroots policies need to be structured and implemented to ensure childhood immunization, early detection and referral of eye diseases by midwives and birth attendants, and prompt treatment of eye diseases by ophthalmologists and eye care providers.

Health education to highlight the importance of educating both male and female children should be embarked upon by stakeholders in the health sector. This could be done via jingles, educational talks, plays on radio and television, flyers, pictures, and songs, all directed at women, nursing mothers, teachers, traditional birth attendants, and care givers These programmes can also be carried out in markets, at schools, hospitals and village squares. They should also be aimed at improving awareness for identification and prevention of common eye problems.

Bearing in mind that most of the students in the four schools studied were over 16 years of age, rehabilitation should not only be educational but also occupational, to equip them with skills that would make them useful in the society.

\section{REFERENCES}

1. Global initiative for the elimination of avoidable blindness. Geneva, WHO 1998 (WHO/PBL/97.61).

2. Preventing blindness in children. Report of a WHO/IAPB Scientific Meeting. Geneve, WHO 2000 (WHO/PBL/00.77).

3. Akinsola FB, Ajaiyeoba AI. Causes of low vision and blindness in children in a blind school in Lagos, Nigeria. West African Journal of Medicine 2002; 21(1): 63-5.

4. Ezegwui IR, Umeh RE. Causes of childhood blindness: Result from schools of the blind in South Eastern Nigeria. British Journal of Ophthalmology 2003; 87: 20-23.

5. Foster A. Medical Report to the Ministry of Health of Ethiopia, 1986. (Unpublished report).

6. Kello AB, Gilbert C. Causes of severe visual impairment and blindness in children in schools for the blind in Ethiopia. British Journal of Ophthalmology 2003; 87(5): 52630.

7. Ntim-Amponsah CT, Amoaku WM. Causes of childhood visual impairment and unmet low-vision care in blind school students in Ghana. Int Ophthalmology 2007; 26. www.population.gov.ng/index.php.htm

8. Gilbert C, Foster A. Childhood blindness in the context of VISION 2020- The Right to Sight. WHO 2001; 79: 227-232.

9. Silver J, Gilbert CE, Spoerer E, Foster A. Low vision in East African blind schools: Need for optical low vision devices. British Journal of Ophthalmology 1995; 79: 814-820.

10. Akinsola FB, Ajaiyeoba AI. Assessment of educational services available to blind and low vision school children in Lagos, Nigeria. West African Journal of Medicine 2002; 21(1): 37-9.

11. Honby SJ, Adolf S, Gothwal VK, Gilbert CE, Dandona L, Foster A. Evaluation of children in six blind schools in Andhra Pradesh. Indian Journal of Ophthalmology 2000; 48(3); 195-200.

12. Gogate P, Deshpande M, Sudrik S, Taras S, Kishore H, Gilbert C. Changing pattern of childhood blindness in Maharashtra, India. British Journal of Ophthalmology 2007; 91(1): 8-12. Epub 2006 Jun 29. 